\title{
Beneficial effect of reduced oxygen concentration with transfer of blastocysts in IVF patients older than $\mathbf{4 0}$ years old
}

\author{
Javier I. García*, Soledad Sepúlveda, Luis Noriega-Hoces \\ Laboratory of Assisted Reproduction, Concebir Clinic, Lima, Peru; *Corresponding Author: jgarciaf@hotmail.com
}

Received 6 February 2010; revised 1 March 2010; accepted 5 March 2010.

\begin{abstract}
The aim of the present study was to determine the impact of oxygen concentration on implantation, pregnancy and delivery rates in IVF patients older than 40 year old with transfer of blastocysts. Included were 558 women aged 23-45 years old undergoing IVF/ICSI procedures whose embryos were cultured at blastocyst stage under two different oxygen environments (a bi-gas system: $5.6 \% \mathrm{CO}_{2}$ in air and a tri-gas system: $5.6 \% \mathrm{CO}_{2}, 5 \%$ de $\mathrm{O}_{2}$ and $89.4 \% \mathrm{~N}_{2}$ ). The main outcome measures of this study are implantation, pregnancy and delivery rates. Implantation, pregnancy and delivery rates are found to be reduced in women older than $\mathbf{4 0}$ years old. The implantation and pregnancy rates are significantly higher in women older than $\mathbf{4 0}$ years old from the $5 \%$ of $\mathrm{O}_{2}$ group, in comparison to the $20 \%$ group $(25.00 \%$ versus $2.70 \%$ and $41.38 \%$ versus $5.56 \% ; P<0.05)$. The deliveries rates were $13.79 \%$ and $5.56 \%$ in the $5 \%$ and $20 \%$ oxygen groups respectively (P: NS). The birthweight was similar in both study groups (P: NS). Gestational age was significantly longer in women from the $5 \%$ of $\mathrm{O}_{2}$ group, in comparison to the $20 \%$ (36.87 versus 35.87 weeks, $P<0.05)$. Results indicated that the embryonic culture with $5 \%$ of oxygen and transfer of blastocysts in women older than $\mathbf{4 0}$ years old improve the results in the in Vitro fertilization/intracytoplasmic injection procedures (IVF/ICSI).
\end{abstract}

Keywords: ART; Blastocyst; IVF; ICSI; Oxygen

\section{INTRODUCTION}

Embryos from several mammal species, including human, were exposed in vivo to low oxygen concentrations, ranging from 2 to $8 \%$ observed in atmospheric air [1-3]. This probably corresponds to an adaptation mechanism, as it is proven that higher oxygen concentrations may be harmful to the embryo [4] by generating reactive oxygen species (ROS) [5-7].

In Vitro fertilization studies (IVF) in mice [8,9]; cattle [5]; sheep [10]; rabbits [11]; hamsters [12]; rats [13]; cows [14] and pigs [15] have demonstrated that when cultured in oxygen concentrations of 5\% present a higher viability and a better development to the blastocyst stage.

However, a pioneer study in human embryos showed that cultures in Vitro in atmospheric concentration (20\%) or reduced $(5 \%)$ resulted in similar fecundation and preimplantational embryo development processes [16]. Therefore, in several laboratories of assisted reproduction, the culture of human embryos using oxygen concentration of $20 \%$ [17] is now a common practice.

Furthermore, a study in which the effect of oxygen over the 2nd and 3rd day of human embryo development was evaluated was unable to find any differences in the pregnancy and implantation rates when $5 \%$ or $20 \%$ of $\mathrm{O}_{2}$ was used [17]. This absence of differences in the results obtained might be because the beneficial effect of low $\mathrm{O}_{2}$ concentrations happen during the late stages of preimplantational embryo development (day 4-6) [18]; however, the addition of antioxidants to the culture media had as a result better rates of implantation and pregnancy when embryos cultured in $5 \%$ of $\mathrm{O}_{2}$ are transferred in the 2nd and 3rd day [5].

The importance of the transfer in blastocyst stage and the concentration of oxygen have been recently recognized $[19,20]$ These studies reported significant increases in the pregnancy and implantation rates when transfers were done in blastocyst stage and when the cultures were made with $5 \%$ of $\mathrm{O}_{2}$ compared to the culture effect in conditions of $20 \%$ of $\mathrm{O}_{2}$.

Physiologically, the uterus provides a nutritional environment different from than in the fallopian tubes. Therefore, embryo transfer in the cleavage stage would 
cause homeostatic stress of the embryo and a reduction in its implantatory potential [21]. Consequently, the transfer in blastocyst stage would allow a better synchronization with rhythm of uterine contractions and the embryo [22,23].

However, there are contradictory results in studies where the human embryos cultured in reduced $(5 \%)$ or atmospheric oxygen concentrations (20\%) are compared. Thus, no improvements in terms of pregnancy and implantation rates were observed if the transfer was performed in the 3rd day of the development in terms of pregnancy and implantation rates [17,20,24]. Similar results have been observed if transfer was done into blastocyst stage (day 5) [24-27].

The maternal age is an important factor to be taken into account in studies on. In fact, there has been a decrease in the women's fertility from 35 years old [28,29], being this reduction significant from the 40 year olds and over, in women attending a processes of assisted reproduction [30,31].

The Latin American Registry of Assisted Reproduction (REDLARA) reported in 2006 a clinical pregnancy rate of $39.6 \%$ in patients $\leq 34$ years old, $32.8 \%$ in patients from 35 to 39 years old and $18.6 \%$ in women $\geq 40$ years old respectively [32]. In older women there is commonly a reduction in the ovarian follicular reserve and a greater prevalence of chromosomal alterations in the oocyte, which lead to a significant reduction in the implantation rates $[33,34]$ and high rates of miscarriages $[35,36]$.

In the studies comparing the effect of different oxygen concentrations in the embryo cultures, it has not been taken into consideration the maternal age impact when blastocysts are transferred in the programs of assisted reproduction [19,25,27,37].

In a recent publication Kovačič et al. [26] did not find improvements in the implantation rates in older women over 40 years of age whose embryos were cultured with oxygen at $5 \%$ as compared cultures at $20 \%$ of $\mathrm{O}_{2}$ and embryo transfer in the 3rd day. It is possible that effects of low oxygen concentration may be observed if embryos are transferred in the 5 th or 6 th days.

We hypothesize that reducing the percentage of oxygen to $5 \%$ in the embryo culture systems would have a much more beneficial effect than the usage of oxygen at $20 \%$.

The objective of this study was to evaluate in an IVF/ICSI program, the relationship between the pregnancy and the implantation rates with maternal age whose embryos were cultured in $5 \%$ of $\mathrm{O}_{2}$, compared to those women whose embryos were cultured at $20 \%$ of $\mathrm{O}_{2}$. In addition, the results of pregnancies were assessed.

\section{MATERIALS AND METHODS}

\subsection{Patients}

This is a retrospective non randomized study based on secondary analysis of data obtained from 558 cycles of IVF and ICSI at the Laboratories of Assisted Reproduction of Pranor Group (Lima, Peru) between January 2007 and June 2009. This study was approved by the Institutional Review Board (IRB) at the Concebir Clinic (Lima, Peru).

The study group were those gametes and embryos cultured at $37^{\circ} \mathrm{C}$ in an atmosphere of $5.6 \% \mathrm{CO}_{2}, 5 \%$ of $\mathrm{O}_{2}$ and $89.4 \% \mathrm{~N}_{2}$ (341 cycles); and a control group of those gametes and embryos cultured at $37^{\circ} \mathrm{C}$ and an atmosphere of $5.6 \% \mathrm{CO}_{2}$ in $\operatorname{air}\left(20 \% \mathrm{O}_{2}\right)(217$ cycles $)$. The same kind of incubators (Thermo Scientific, USA) was used for the bi-gas and tri-gas systems.

\subsection{Ovarian Stimulation and Oocyte Collection}

The patients were submitted to a controlled ovarian stimulation with Leuprolide Acetate (Lupron $\AA$, Abbott Laboratories) or Ganirelix (Orgalutran $\AA$, Organon) in combination with Recombinant FSH (Puregon ${ }^{\circledR}$, Organon Laboratories) or HMG (Humegon $\AA$, Organon Laboratories) according to the established protocols. The follicular growth was monitored by ultrasound and the ovulation was induced by applying Human Chorionic Gonadotropin (hCG) (Ovidrel® $250 \mathrm{ug}$, Serono Laboratories or Pregnyl ${ }^{\circledR} 10,000$ UI, Organon Laboratories). The follicular aspiration was made 34 to 36 hours after giving the hCG. The insemination or ICSI procedure was made-5 hours after the oocyte recovery.

\subsection{Semen Samples}

The semen samples were obtained by masturbation of every patient's male in aseptic conditions. After the liquefaction process, the motile spermatozoa were recovered from the seminal plasma by centrifugation through Isolate gradients of $45 \%$ and $95 \%$ (Irvine Scientific, USA) for 10 minutes at $300 \times \mathrm{g}$. the recovered spermatozoa were washed in Sperm Washing Media (Irvine Scientific, USA). In oligospermic samples the spermatozoa were washed in Sperm Washing Media and then placed in $10 \mu \mathrm{L}$ drops of HTF-Hepes $+10 \%$ SSS for the ICSI.

\subsection{Fertilization and Embryo Culture}

In each one of the evaluated groups, the embryo culture media and mineral oil were prepared and used according to the specifications of the company. The $\mathrm{CO}_{2}$ concentration in the incubators was of $5.6 \%$ and resulting $\mathrm{pH}$ 
was approximately 7.30 in all the culture media.

The aspired oocytes were washed in a HTF-Hepes medium (IVFonline, Guelph, ON, Canada) supplemented with $10 \% \mathrm{vol} / \mathrm{vol}$ of SSS (Irvine Scientific, USA) and cultured in a $200 \mu \mathrm{L}$ drop of HTF medium $+10 \%$ SSS under mineral oil at $37^{\circ} \mathrm{C}$ for 5 hours before the insemination or ICSI procedure.

The insemination was made with 50,000-100,000 motile spermatozoa in $200 \mu \mathrm{L}$ drop of HTF medium $+10 \%$ $\mathrm{SSS}$, where from 1 to 5 oocytes were placed. In the cases of ICSI, the oocytes in metaphase II were injected in every patient by using methods previously described (38). After the insemination or ICSI in 0 day, all the oocytes were cultured up to the evaluation of the fertilization at $37^{\circ} \mathrm{C}$.

The fertilization was evaluated $16-18$ hours post insemination or ICSI by the presence of two pronuclei and two polar bodies (day 1). The zygotes with two pronuclei were cultured individually, under mineral oil, in 10 $\mu \mathrm{L}$ drops of Global medium (IVFonline, Guelph, ON, Canada) supplemented with 10\% vol/vol of SSS (Irvine Scientific, USA) from day 1 to day 3. On the 3rd day, the embryos were changed to $10 \mu \mathrm{L}$ drops of fresh Global medium $+10 \%$ SSS and cultured 2 or 3 days more up to the transfer day in blastocyst stage. Therefore, the transfer was made in 5 or 6 days.

\subsection{Embryo Transfer}

The embryos were transferred in blastocyst stage, being the average of 1.96 and 2 embryos transferred in the group of $5 \%$ and $20 \%$ of $\mathrm{O}_{2}$ respectively $(\mathrm{P}<0.05$ among the evaluated groups). In the $5 \%$ of $\mathrm{O}_{2}$ group, 16 patients received 1 embryo, 324 received 2 embryos and 1 patient received 3 embryos. In the $20 \%$ of $\mathrm{O}_{2}$ group, 4 patients received 1 embryo, 209 patients received 2 embryos and 4 patients received 3 embryos (Table 1).

The embryos that were not transferred were cryopreserved or eliminated according to their morphology. The embryo transfer was made with a Frydman Ultrasoft catheter (CCD Laboratoire, Paris, France) that was previously washed with a culture medium. The catheter was completely filled with culture medium and the embryos filled in the last $10 \mu \mathrm{L}$ of the catheter medium. All the transfers were made according to the methods previously described by Mansour [39].

The biochemical pregnancy was determined approximately 12 to 14 days after the embryo transfer by measuring the Human Chorionic Gonadotropin beta subunit (hCG-b) in blood. The clinical pregnancy was determined by the presence of the gestational sac and the heart beat which were evaluated by ultrasound at the 21 st and 28 th days post transfer respectively.

\subsection{Statistical Analysis}

Data were statistically analyzed using the $\chi^{2}$ test and Student's t-test as appropriate and differences were considered to be significant at $\mathrm{P}<0.05$. All statistical analysis was carried out using the statistic package Stata 10 (StataCorp, College Station, TX).

In this study, the cycles were organized in 3 segments according to the age of the patient: $<35$ years old, 35-39 years old and $\geq 40$ years old. The normal fertilization rate was calculated from the number of zygotes with two pronuclei of IVF and ICSI divided by the number of mature oocytes inseminated by 100 . The rate of implantation was calculated dividing the number of gestational sacs observed by ultrasound at the 21 st day post transfer divided by the total number of embryos transferred by 100. The rate of clinic pregnancy was calculated from the number of patients with at least one gestational sac divided by the total embryo transfers by 100 . The abortion rate was defined as the number of pregnancies with total loss of the gestational sacs before the 20 weeks of gestation between the numbers of pregnancies by 100 .

\section{RESULTS}

A total of 558 cycles in which the embryos were cultured under two different $\mathrm{O}_{2}$ environments were evaluated; embryos of 341 and 217 cycles were cultured in 5\% and $20 \%$ of $\mathrm{O}_{2}$ respectively. The age of the patients was similar in both evaluated groups (P: NS). The fertilization rate was similar in the $5 \%$ of $\mathrm{O}_{2}$ group versus the $20 \%$ in each age group evaluated in this study (Table 2).

Table 1. Characteristics of the two study groups whose embryos were cultured in $5 \%$ or $20 \%$ of $\mathrm{O}_{2}$.

\begin{tabular}{ccc}
\hline & $\mathbf{5 \%} \mathbf{O}_{\mathbf{2}}$ & $\mathbf{2 0 \%} \mathbf{O}_{\mathbf{2}}$ \\
\hline Cycles & 341 & 217 \\
Age (y) & & \\
Range & $25-45$ & $23-45$ \\
Mean \pm SE & $34.47 \pm 0.20$ & $34.33 \pm 0.26$ \\
Indication & & \\
Tubal Factor & $37(11)$ & $16(7)$ \\
Other female & $161(47)$ & $95(44)$ \\
Male Factor & $48(14)$ & $29(13)$ \\
Multiple Factor & $88(26)$ & $72(33)$ \\
Unexplained & $7(2)$ & $5(3)$ \\
Procedure Class & & \\
Standard IVF & $194(57)$ & $96(44)$ \\
ICSI & $147(43)$ & $121(56)$ \\
\hline
\end{tabular}

Data are Mean \pm Standard Error; ${ }^{\text {a } V a l u e s ~ i n ~ p a r e n t h e s e s ~ a r e ~ p e r c e n t a g e s ~ o f ~}$ the total number of patients; P: NS. 
Table 2. Implantation rate, pregnancy rate, abortion rate and birth rate by age group in cycles with embryos cultured in atmosphere of $5 \%$ and $20 \%$ of oxygen.

\begin{tabular}{|c|c|c|c|c|c|c|}
\hline & \multicolumn{2}{|c|}{$<35$ years } & \multicolumn{2}{|c|}{ 35-39 years } & \multicolumn{2}{|c|}{$\geq 40$ years } \\
\hline & $5 \% \mathrm{O}_{2}$ & $20 \% \mathrm{O}_{2}$ & $5 \% \mathrm{O}_{2}$ & $20 \% \mathrm{O}_{2}$ & $5 \% \mathrm{O}_{2}$ & $20 \% \mathrm{O}_{2}$ \\
\hline Cycles & 169 & 108 & 143 & 91 & 29 & 18 \\
\hline Fertilization rate (\%) & 83.03 & 79.78 & 84.04 & 78.16 & 83.52 & 81.60 \\
\hline Transferred embryos & $1.98 \pm 0.01$ & $1.99 \pm 0.02$ & $1.93 \pm 0.02^{\mathrm{b}}$ & $2.00 \pm 0.02$ & $1.93 \pm 0.05^{\mathrm{a}}$ & $2.06 \pm 0.01$ \\
\hline Implantation rate $(\%)$ & 34.63 & 35.81 & 26.09 & 26.92 & $25.00^{\mathrm{a}}$ & 2.70 \\
\hline Clinical Pregnancy rate $(\%)$ & 50.89 & 51.85 & 42.66 & 42.86 & $41.38^{\mathrm{a}}$ & 5.56 \\
\hline Abortion rate $(\%)$ & 5.92 & 7.41 & 7.69 & 10.99 & $17.24^{\mathrm{c}}$ & 00.00 \\
\hline Birth per transfer rate $(\%)$ & 42.59 & 44.44 & 32.12 & 31.87 & 13.79 & $5.56^{\mathrm{d}}$ \\
\hline Ongoing pregnancy & 7 & 0 & 6 & 0 & 3 & 0 \\
\hline
\end{tabular}

Data are Mean \pm Standard Error; ${ }^{a} \mathrm{P}<0.05$ compared to the average in patients $\geq 40$ years old from the $20 \% \mathrm{O}_{2}$ group; ${ }^{b} \mathrm{P}<0.05$ compared to the average in patients of $35-39$ years old from the $20 \% \mathrm{O}_{2}$ group; ${ }^{\mathrm{C}}<0.05$ compared to the average in patients of $<35$ years old from the $5 \% \mathrm{O}_{2}$ group; ${ }^{d} \mathrm{P}<0.05$ compared to the average in patients of $<35$ years old from the $5 \%$ and $20 \% \mathrm{O}_{2}$ group.

The patients $\geq 40$ years old from $5 \%$ group of $\mathrm{O}_{2}$ had implantation and pregnancy rates significantly higher compared to those patients from $20 \%$ of $\mathrm{O}_{2}$ group $(\mathrm{P}<$ 0.05). Furthermore, these patients older than 40 years old from the $5 \%$ of $\mathrm{O}_{2}$ group received a significantly less number of embryos transferred, compared to the patients from $20 \%$ group $(\mathrm{P}<0.05)$. The group of patients $<35$ years old and of 35-39 years old had similar implantation and pregnancy rates (P: NS).

Women $\geq 40$ years old from $5 \%$ of $\mathrm{O}_{2}$ group had a higher abortion rate compared to women $<35$ years old from the same study group $(\mathrm{P}<0.05)$. However, in the group of patients whose embryos were cultured in $20 \%$ of $\mathrm{O}_{2}$, the older women ( $\geq 40$ years old) had a lower delivery rates in comparison to women $<35$ years old in both evaluated groups $\left(5 \%\right.$ and $20 \%$ of $\left.\mathrm{O}_{2}\right)(\mathrm{P}<0.05)$. In women $\geq 40$ years old from $20 \%$ of $\mathrm{O}_{2}$ group there was only 1 pregnancy out of 18 transfers, which resulted in a healthy born baby. In the $5 \%$ of $\mathrm{O}_{2}$ group there were 12 pregnancies from which 5 women had an abortion before the 20th week of gestation, 4 had a normal delivery and 3 pregnancies have a normal development. The delivery rate was similar in women older than 40 years of age in the $5 \%$ of $\mathrm{O}_{2}$ group compared to the $20 \%$ of $\mathrm{O}_{2}$ group $(13.79 \%$ vs. $5.56 \%$; $\mathrm{P}>0.05)$.

The pregnancy rates according to the kind of procedure of IVF or ICSI were similar among both procedures in the evaluated groups $\left(5 \%\right.$ and $20 \%$ of $\left.\mathrm{O}_{2}\right)$ in women $<$ 35 years old, 35-39 years old and older than 40 years old. Less pregnancies were achieved in women $\geq 40$ years old when their embryos were cultured in a $20 \%$ of $\mathrm{O}_{2}$ atmosphere, independently from the kind of procedure of IVF or ICSI, in comparison to the group of women $<35$ years old and of 35-39 years old $(\mathrm{P}<0.05)$ (data not shown).

The percentage of embryos that reached the blastocyst stage in relation to the total number of fertilized oocytes is show in Table 3. There were no differences in the embryonic blastulation rate among patients from the 5\% and $20 \%$ of $\mathrm{O}_{2}$ group; these percentages were equally similar in relation to the age of the patients. Furthermore, there was no difference in the pregnancy rates according to the kind of controlled ovarian stimulation in both evaluated groups in this study (Table 4).

The data about the gestational age at delivery and birth weight from both groups evaluated in this study is shown in Table 5. There were 87 deliveries in the 5\% of $\mathrm{O}_{2}$ group and 78 deliveries in the $20 \%$ of $\mathrm{O}_{2}$ group. However, it was only possible to register information from 39 and 60 in each group respectively. Gestational age was higher in women whose embryos were cultured in reduced concentrations of oxygen, in comparison to those women whose embryos were cultured in atmospheric concentrations of oxygen $(\mathrm{P}<0.05)$ (Table 5).

Table 3. Blastulation rate according to age in both study groups.

\begin{tabular}{cccc}
\hline & $\mathbf{5 \%} \mathbf{~ O}_{\mathbf{2}}$ & $\mathbf{2 0 \%} \mathbf{O}_{\mathbf{2}}$ & $\mathbf{P}$ \\
\hline Cycles & 341 & 217 & \\
No. of embryos (2PN) & 2281 & 1612 & \\
$<35$ years old & $39.82 \%$ & $37.59 \%$ & 0.487 \\
35-39 years old & $36.11 \%$ & $39.69 \%$ & 0.348 \\
$\geq 40$ years old & $34.01 \%$ & $31.37 \%$ & 0.756 \\
Total & $37.97 \%$ & $37.97 \%$ & 1.000 \\
\hline
\end{tabular}

P: NS 
Table 4. Pregnancy rate according to the protocol of ovarian stimulation with agonist or antagonist from the GnRH (GnRHa -GnRHant) and the recombinant $\mathrm{FSH}(\mathrm{rFSH})$ or human menopausal gonadotropin (HMG) in the study groups.

\begin{tabular}{ccc}
\hline Stimulation Protocol & $\mathbf{5 \%} \mathbf{O}_{2}$ & $\mathbf{2 0 \%} \mathbf{O}_{2}$ \\
\hline GnRHa + rFSH & $60.00 \%$ & $36.84 \%$ \\
GnRHa + HMG & $50.00 \%$ & $40.00 \%$ \\
GnRHa + rFSH + HMG & $45.45 \%$ & $53.33 \%$ \\
GnRHant + rFSH & $50.43 \%$ & $41.67 \%$ \\
GnRHant + HMG & $55.00 \%$ & $50.00 \%$ \\
GnRHant + rFSH + HMG & $48.21 \%$ & $60.87 \%$ \\
rFSH & $27.27 \%$ & $43.75 \%$ \\
HMG & $57.14 \%$ & $40.00 \%$ \\
rFSH + HMG & $35.71 \%$ & $38.89 \%$ \\
\hline
\end{tabular}

P: NS

Table 5. Gestational age and birth weight in the study groups.

\begin{tabular}{cccc}
\hline & $\mathbf{5 \%} \mathbf{O}_{2}$ & $\mathbf{2 0 \%} \mathbf{O}_{2}$ & $\mathbf{P}$ \\
\hline Biochemical pregnancy & 5 & 4 & \\
Clinical pregnancy & 159 & 96 & \\
Total delivery & 87 & 78 & \\
Deliveries with recorded data & 39 & 60 & $<0.05$ \\
$\begin{array}{c}\text { Gestational age } \\
(\text { weeks) (Mean } \pm \text { SE) }\end{array}$ & $36.87 \pm 0.30$ & $35.87 \pm 0.37$ & \\
$\begin{array}{c}\text { Bithweight of newborns } \\
\text { (gr.) (Mean } \pm \text { SE) }\end{array}$ & $2816.26 \pm 92.882752 .96 \pm 69.05$ & NS \\
\hline
\end{tabular}

${ }^{\mathrm{a}}$ Data are Mean \pm Standard Error

\section{DISCUSSION}

Although human embryos can develop successfully in atmospheric concentrations of oxygen (20\%), some authors have suggested that low oxygen concentrations $(5 \%)$ resemble the physiological conditions of the uterus effectively, and thereby improve the quality, viability and embryo morphology $[40,41]$.

An important result of this study was to find that culturing embryos at reduced concentrations of $\mathrm{O}_{2}(5 \%)$ is beneficial to patients $\geq 40$ years old who perform assisted reproductive procedures with their own oocyte; these are the ones who achieve significantly higher implantation and pregnancy rates compared to those patients of similar age whose embryos were cultured under atmospheric oxygen concentrations (20\%) $(25.00 \%$ versus $2.70 \% ; 41.38 \%$ versus $5.56 \%$, respectively, $\mathrm{P}<0.05)$.
The implantation and pregnancy rates observed in women $>40$ years old were similar to those seen in women $<35$ years old and 35-39 years old (P:NS).

Meintjes et al. (20) embryos cultured in a $5 \% \mathrm{O}_{2}$ environment consistently resulted in higher rates of live birth implantation and live births when compared with rates among women whose embryos were cultured in an atmospheric $\mathrm{O}_{2}$ environment.

Furthermore, Nanassy et al. [27] cultured human embryos under oxygen atmospheric conditions (20\%) until the 3rd day and then cultured the embryos in 5\% and $20 \%$ of $\mathrm{O}_{2}$ from the 3 rd to the 5 th day of development without finding beneficial effects of $5 \%$ of $\mathrm{O}_{2}$ in the advanced stages of preimplantational embryo development. These results suggest that the beneficial effect of hypoxia on embryonic development would be along all stages of in vitro cultures even from the oocyte before fertilization up to the blastocyst stage [42], which had previously been observed in mice $[8,43]$ cattle [44], rabbits [45] and pigs [46].

Culturing embryos in $20 \%$ of $\mathrm{O}_{2}$, Karagenc [7] showed damage mainly in the embryonic inner cell mass (ICM). Similarly, Rhesus monkey embryo cultured in vitro in $20 \%$ of $\mathrm{O}_{2}$ showed the ICM morphologically disorganized, diffuse, with few vacuolated cells, unlike the blastocysts with large and compact ICM cultured in low concentrations of $\mathrm{O}_{2}$ [47].

Rho et al. [48] culturing bovine embryos has shown that low concentrations of oxygen produce higher rates of cleavage and blastocyst stages compared to embryos cultured in $20 \%$ of $\mathrm{O}_{2}$. Also in mice there is a better development to blastocyst stage, bigger number and size of ICM, and gene expression profile similar to those observed in embryo in vivo [49].

The discrepancies between the data obtained in animals and humans could be explained based on the differences in the embryo physiology of each species and a variety of culture conditions and embryo transfer in the laboratory [47]. Beneficial effects of culture in $5 \%$ of $\mathrm{O}_{2}$ have been demonstrated in animals where embryo transfers routinely occur in blastocyst stage [7,50].

Dumoulin et al. [18], Pabon et al. [8], Quinn and Harlow [43] suggested that the beneficial effect of $\mathrm{O}_{2}$ in physiological concentrations should be observed in cultures extended to blastocyst, which are nowadays common in assisted reproduction laboratories.

Several studies report increases in pregnancy and implantation in blastocyst transfers compared to embryo transfers on the 3rd day [51] and others report significant increases only in implantation rates [52], which considering the results of this study, would have beneficial effects in those patients over 40 years old.

The culture up to the blastocyst would allow to choose 
in a more "natural" way embryos with greater potential for development and implantation, however, this selection would also depend on the $\mathrm{O}_{2}$ percentage in the systems in which the embryos are cultured [47] and the oocyte origin associated to the patient's age $[53,54]$.

There are many authors who have showed the relationship between chromosomal abnormalities, maternal age and embryo morphology [35,55-59]. Munné et al. [54] performed genetic diagnosis for 9 chromosomes $[13,15-18,21,22, \mathrm{X}, \mathrm{Y})$ in $>6000$ embryos and found that women $<35$ years old with good quality embryos had $44 \%$ of euploid embryos and that this percentage decreased to $21 \%$ in patients $\geq 41$ years old. Beside, in patients with poor morphology embryos only $30 \%$ and $12 \%$ were euploid embryos in the group of women $>35$ years old and $\geq 41$ years old respectively. It has also been shown that chromosomal abnormalities in human oocytes are common and that these aneuploidies are closely related to maternal age, exceeding $60 \%$ in women over 40 years old [60].

Since older women have a higher incidence of oocytes and embryos with aneuploidy $[54,60]$ but with similar rates of embryonic blastulation than young women $(\leq 35$ years old, 35-39 years old; see Table 3) as it has been demonstrated in this study, we should expect similar pregnancy and implantation rates independently from the oxygen concentration under which cultures in vitro are performed, but in this study we found that low concentrations of oxygen $(5 \%)$ are achieved significantly higher pregnancy and implantation rates in patients $\geq 40$ years old, compared to the results in conditions of atmospheric concentrations of oxygen.

These results might be caused by high concentrations of oxygen that would affect the embryonic inner cell mass [7], an effect that would be even more noticeable because of the high incidence of aneuploidy observed in oocytes and embryos in older women.

In this study there were 87 births in the $5 \%$ of $\mathrm{O}_{2}$ group and 78 births in the group of $20 \%$, being able to obtain information of their results, in terms of gestational age and birthweight, in 39 and 60 cases respectively.

Within the data obtained, a significantly higher gestational age was observed in the group of patients whose embryos were cultured under $5 \% \mathrm{O}_{2}$ compared to the $20 \%$ of $\mathrm{O}_{2}$ group $(36.87 \pm 0.30$ vs. $35.87 \pm 0.37 ; \mathrm{P}<$ 0.05 ) which could be a consequence of preimplantational embryo development in more physiological concentrations of oxygen to which the embryos were subjected during in vitro culture, but we believe that further studies are needed to determinate the possible relationship between the culture in hypoxic conditions and obstetric characteristics of pregnancies.

\section{ACKNOWLEDGEMENTS}

The authors thank to Gustavo F. Gonzales M.D, Ph.D. for his valuable help and his review of this manuscript.

\section{REFERENCES}

[1] Bayatt-Smith, J.G., Leese, H.J. and Gosden, R.G. (1991) An investigation by mathematical modeling of whether Mouse and human preimplantation embryos in static culture can satisfy their demands for oxygen by diffusion. Human Reproduction, 6(1), 52-57.

[2] Fisher, B. and Bavister, B.D. (1993) Oxygen tension in the oviduct and uterus of rhesus monkeys, hamsters and rabbits. Journal of Reproduction and Fertility, 99(2), 673-679.

[3] Yedwab, G.A., Paz, G., Homonnai, T.Z., David, M.P. and Kraicer, P.F. (1976) Temperature, $\mathrm{pH}$ and partial pressure of oxygen in the cervix and uterus of women and uterus of rats during the cycle. Fertility and Sterility, 27(3), 304-309.

[4] Johnson, M.H. and Nasr-Esfahani, M.H. (1994) Radical solutions and cultural problems: Could free oxygen radicals be responsible for the impaired development of preimplantation mammalian embryos in vitro? Bioassays, 16(1), 31-38.

[5] Catt, J.W. and Henman, M. (2000) Toxic effects of oxygen on human embryo development. Human Reproduction, 15(Suppl. 2), 199-206.

[6] Bavister, B.D. (1995) Culture of preimplantation embryos: Facts and artifacts. Human Reproduction Update, 1(2), 91-148.

[7] Karagenc, L., Sertkaya, Z. and Ciray, N. (2004) Impact of oxygen concentration on embryonic development of mouse zygotes. Reproductive BioMedicine Online, 9(4), 409-417.

[8] Pabon, J.E., Jr, Findley, W.E. and Gibbons, W.E. (1889) The toxic effect of short exposures to the atmospheric oxygen concentration on early mouse embryonic development. Fertility and Sterility, 51(5), 896-900.

[9] Umaoka, Y., Noda, Y. and Narimoto, K. (1992) Effects of oxygen toxicity on early development of Mouse embryos. Molecular Reproduction and Development, 31(1), 28-33.

[10] Thompson, J.G., Simpson, A.C., Pugh, P.A., Donnelly, P.E. and Tervit, H.R. (1990) Effect of oxygen concentration on in-vitro development of preimplantation sheep and cattle embryos. Journal of Reproduction and Fertility, 89(2), 573-578.

[11] Li, J., Foote, R.H. and Simkin, M. (1993) Development of rabbit zygotes cultured in protein-free medium with catalase, taurine or superoxide dismutase. Biology of Reproduction, 49(1), 33-37.

[12] McKiernan, S.H. and Bavister, B.D. (1990) Environmental variables influencing in vitro development of hamster 2 cell embryos to the blastocyst stage. Biology of Reproduction, 43(3), 404-413.

[13] Kishi, J., Noda, Y. and Narimoto, K. (1998) Block to development in cultured rat 1-cell embryos is overcome using medium HECM-1. Human Reproduction, 6(10), $1445-1448$ 
[14] Fukui, Y., McGrowan, L.T. and James, R.W. (1991) Factors affecting the in-vitro development to blastocysts of bovine oocytes matured and fertilized in vitro. Journal of Reproduction and Fertility, 92(1), 125-131.

[15] Kitagawa, Y., Suzuki, K. and Yoneda, A. (2004) Effects of oxygen concentration and antioxidants on the in vitro developmental ability, production of reactive oxygen species (ROS) and DNA fragmentation in porcine embryos. Theriogenology, 62(7), 1186-1197.

[16] Dumoulin, J., Vanvuchelen, R. and Land, J. (1995) Effect of oxygen concentration on in-vitro fertilization and embryo transfer. Fertility and Sterility, 63(1), 115-119.

[17] Bahçeci, M., Çiray, H.N., Karagenc, L., Uluğ, U. and Bener, F. (2005) Effect of oxygen concentration during the incubation of embryos of women undergoing ICSI and embryo transfer: A prospective randomized study. Reproductive BioMedicine Online, 11(4), 438-443.

[18] Dumoulin, J.C.M., Meijers, C.J.J. and Bras, M. (1999) Effect of oxygen concentration on human in-vitro fertilization and embryo culture. Human Reproduction, 14(2), 465-469.

[19] Waldenström, U., Engström, A., Hellberg, D., Nilsson, S. (2009) Low-oxygen compared with high-oxygen atmosphere in blastocyst culture, a prospective randomized study. Fertility and Sterility, 91(6), 2461-2465.

[20] Meintjes, M., Chantilis, S., Douglas, J., Rodriguez, A., Guerami, A., Bookout, D., Barnett, B. and Madden, J. (2009) A controlled randomized trial evaluating the effect of lowered incubator oxygen tension on live births in a predominantly blastocyst transfer program. Human Reproduction, 24(2), 300-307.

[21] Gardner, D.K., Lane, M., Calderon, I. and Leeton, J. (1996) Environment of the preimplantation human embryo in vivo: Metabolite analysis of oviduct and uterine fluids and metabolism of cumulus cells. Fertility and Sterility, 65(2), 349-53.

[22] Fanchin, R., Ayoubi, J.M., Righini, C., Olivennes, F., Schonauer, L.M. and Frydman, R. (2001) Uterine contractility decreases at the time of blastocyst transfers. Human Reproduction, 16(6), 1115-1119.

[23] Quea, G., Romero, K., García-Velasco, J.A. (2007) Extended embryo culture to increase implantation rate. Reproductive Biomedicine Online, 14(3), 375-383.

[24] Kea, B., Gebhardt, J., Watt, J., Westphal, L.M., Lathi, R.B. and Milki, A.A. (2007) Effect of reduced oxygen concentrations on the outcome of in vitro fertilization. Fertility and Sterility, 87(1), 213-216.

[25] Kovačič, B. and Vlaisavljević, V. (2008) Influence of atmospheric versus reduced oxygen concentration on development of human blastocysts in vitro: a prospective study on sibling oocytes. Reproductive BioMedicine Online, 2(2), 229-236.

[26] Kovačič, B., Sajko, M. and Vlaisavljević, V. (2010) A prospective randomized trial on the effect of atmospheric versus reduced oxygen concentration on the outcome on intracytoplasmic sperm injection cycles. Fertility and Sterility, 94(2), 511-519.

[27] Nanassy, L., Peterson, A., Wilcox, A., Peterson, M., Hammoud, A. and Carrell, D. (2010) Comparison of 5\% and ambient oxygen during days 3-5 in vitro culture of human embryos. Fertility and Sterility, 93(2), 579-585.

[28] Perheentupa, A. and Huhtaniemi, I. (2009) Aging of the human ovary and testis. Journal of Molecular Cell and Endocrinology, 299(1), 2-13.

[29] Steiner, A.Z. (2009) Clinical implications of ovarian reserve testing. Obstetrical and Gynecological Survey, 64(2), 120-128.

[30] Sauer, M.V., Paulson, R.J. and Lobo, R.A. (1992) Reversing the natural decline in human fertility. An extended clinical trial of oocytes donation to women of advanced reproductive age. Journal of the American Medical Association, 268(10), 1275-1279.

[31] Marcus, S.F. and Brinsden, P.R. (1996) In-vitro fertilization and embryo transfer in women aged 40 years and over. Human Reproduction Update, 2(6), 459-468.

[32] Registro Latinoamericano de Reproducción Asistida (2006) Editado por la Red Latinoamericana de Reproducción Asistida. Redlara, Chile, 1-95.

[33] Bar-Hava, I., Orvierto, R., Ferber, A., Ashkenazi, J., Dicker, D. and Ben-Rafael, Z. (1999) Standard in vitro fertilization or intracytoplasmic sperm injection in advanced female age, what may be expected? Gynecology and Endocrinology, 13(2), 93-97.

[34] Munné, S., Cohen, J. and Sable, D. (2002) Preimplantation genetic diagnosis for advanced maternal age and other indications. Fertility and Sterility, 78(2), 234-236.

[35] Munné, S., Alikani, M., Tomkin, G., Grifo, J. and Cohen, J. (1995) Embryo morphology, developmental rates, and maternal age are correlated with chromosomal abnormalities. Fertility and Sterility, 64(2), 382-391.

[36] Nybo Andersen, A.M., Wohlfahrt, J., Christens, P., Olsen, J. and Melbye, M. (2000) Maternal age and fetal loss: Population based register linkage study. British Medical Journal, 320(7251), 1708-1712.

[37] Ciray, H.N., Aksoy, T., Yaramanci, K., Karayaka, I. and Bahçeci, M. (2009) In vitro culture under physiologic oxygen concentration improves blastocyst yield and quality: a prospective randomized survey on sibling oocytes. Fertility and Sterility, 91(Suppl. 1), 1459-1461.

[38] García, J.I., Gonzales, G.F. and Noriega-Hoces, L. (2007) Sperm chromatin stability and its relationship with fertilization rate after Intracytoplasmic Sperm Injection (ICSI) in an assisted reproduction program. Journal of Assisted Reproduction and Genetics, 24(12), 587-593.

[39] Mansour, R. (2005) Minimizing embryo expulsion after embryo transfer: A randomized controlled study. Human Reproduction, 20(1), 170-174.

[40] Gardner, D., Lane, M. (2001) Embryo culture in textbook of assisted reproductive techniques: laboratory and clinical perspectives. In: Gardner, D., Weissman, A., Howles, C. and Shoham, Z., Eds., Martin Dunitz Press, London, 203-222.

[41] Burton, G.J., Hempstock, J. and Jauniaux, E. (2000) Oxygen, early embryonic metabolism and free radical-mediated embryopathies. Reproductive Biomedicine Online, 6(1), 8496.

[42] Adam, A.A., Takahashi, Y., Katagiri, S. and Nagano, M. (2004) Effects of oxygen in the gas atmosphere during in vitro maturation, in vitro fertilization and in vitro culture on the efficiency of in vitro production of mouse embryos. Japan Journal Veterinary Research, 52(2), 77-84.

[43] Quinn, P. and Harlow, G.M. (1978) The effect of oxygen on the development of preimplantation mouse embryo in vitro. Journal of Experimental Zoology, 206(1), 73-80. 
[44] Takahashi, Y. and Kanagawa, H. (1998) Effect of oxygen concentration in the gas atmosphere during in vitro insemination of bovine oocytes on the subsequent embryonic development in vitro. Journal of Veterinary Medical Science, 60(3), 365-367.

[45] Farrell, P.B. and Foote, R.H. (1995) Beneficial effects of culturing rabbit zygotes to blastocysts in 5\% oxygen and $10 \%$ carbon dioxide. Journal of Reproduction and Fertility, 103(1), 127-130.

[46] Im, G.S., Lai, L., Liu, Z., Hao, Y., Wax, D., Bonk, A. and Prather, R.S. (2004) In vitro development of preimplantation porcine nuclear transfer embryos cultured in different media and gas atmospheres. Theriogenology, 61(6), 1125-1135.

[47] Bavister, B.D. (2004) The role of animal studies in supporting human ART. Reproduction Fertility and Development, 16(7), 719-728.

[48] Rho, G.J., Kim, D.S., Son, W.J., Cho, S.R., Kim, J.G., MK, B. and Choe, S.Y. (2007) Influence of in vitro oxygen concentrations on preimplantation embryo development, gene expression and production of Hanwoo calves following embryo transfer. Molecular Reproduction and Development, 74(4), 486-496.

[49] Rinaudo, P.F., Giritharan, G., Talbi, S., Dobson, A.T., Schultz, R.M. (2006) Effects of oxygen tension on gene expression in preimplantation mouse embryos. Fertility and Sterility, 86(Suppl. 4), 1252-1265.

[50] Umaoka, Y., Noda, Y. and Narimoto, K. (1991) Developmental potentiality of embryos cultured under low oxygen tension with superoxide dismutase. Journal of In Vitro Fertilization and Embryo Transfer, 8(5), 245-249.

[51] Chang, H.J., Lee, J.R., Jee, B.C., Suh, C.S. and Kim, S.H. (2009) Impact of blastocyst transfer on offspring sex ratio and the monozygotic twinning rate: A systematic review and meta-analisys. Fertility and Sterility, 91(6), 2381-2390.

[52] Beesley, R., Robinson, R., Propst, A., Arthur, N. and Retzloff, M. (2009) Impact of day 3 or day 5 embryo transfer on pregnancy rates and multiple gestations. Fer- tility and Sterility, 91(5), 1717-1720.

[53] Shapiro, B., Richter, K.S., Harris, D.C. and Daneshmand, S. (2002) Influence of patient age on the growth and transfer blastocyst-stage embryos. Fertility and Sterility, 77(4), 700-705.

[54] Munné, S., Chen, S., Colls, P., Garrisi, J., Zheng, X., Cekleniak, N., Lenzi, M., Hughes, P., Fisher, J., Garrisi, M., Tomkin, G. and Cohen, J. (2007) Maternal age, morphology, development and chromosome abnormalities in over 6000 cleavage-stage embryos. Reproductive Biomedicine Online, 14(5), 628-634.

[55] Munné, S., Bahçe, M., Sandalinas, M., Escudero, T., Márquez, C., Velilla, E., Colls, P., Oter, M., Alikani, M. and Cohen, J. (2004) Differences in chromosomes susceptibility to aneuploidy and survival to first trimester Reproductive Biomedicine Online, 8(1), 81-90.

[56] Magli, M.C., Gianaroli, L. and Ferraretti, A.P. (2001) Chromosomal abnormalities in embryos. Molecular and Cellular Endocrinology, 183(Suppl. 1), S29-S34.

[57] Bielanska, M., Tan, S.L. and Ao, A. (2002a) Chromosomal mosaicism throughout human preimplantation development in vitro: incidence, type and relevance to embryo outcome. Human Reproduction, 17(2), 413-419.

[58] Gianaroli, L., Magli, M.C. and Ferraretti, A.P. (2007) Oocyte euploidy, pronuclear zygotes morphology and embryo chromosomal complement. Human Reproduction, 22(1), 241-249.

[59] Munné, S. (2006) Chromosome abnormalities and their relationship to morphology and development of human embryos. Reproductive Biomedicine Online, 12(2), 234253.

[60] Fragouli, E., Alfarawati, S., Katz-Jaffe, M., Alfarawati, S., Stevens, J., Colls, P., Goodall, N.N., Tormasi, S., GutierrezMateo, C., Prates, R., Schoolcraft, W.B., Munné, S. and Wells, D. (2010) Comprehensive chromosome screening of polar bodies and blastocysts from couples experiencing repeated implantation failure. Fertility and Sterility, 94(3), 875-887. 